\title{
The use of airborne LiDAR data for the analysis of debris flow events in Switzerland
}

\author{
C. Scheidl ${ }^{1}$, D. Rickenmann ${ }^{1,2}$, and M. Chiari ${ }^{1}$ \\ ${ }^{1}$ Institute of Mountain Risk Engineering, University of Natural Resources and Applied Life Sciences, Vienna, Austria \\ ${ }^{2}$ Swiss Federal Research Institute WSL, Birmensdorf, Switzerland
}

Received: 7 May 2008 - Revised: 21 August 2008 - Accepted: 21 August 2008 - Published: 16 October 2008

\begin{abstract}
A methodology of magnitude estimates for debris flow events is described using airborne LiDAR data. Light Detection And Ranging (LiDAR) is a widely used technology to generate digital elevation information. LiDAR data in alpine regions can be obtained by several commercial companies where the automated filtering process is proprietary and varies from companies to companies. This study describes the analysis of geomorphologic changes using digital terrain models derived from commercial LiDAR data. The estimation of the deposition volumes is based on two digital terrain models covering the same area but differing in their time of survey. In this study two surveyed deposition areas of debris flows, located in the canton of Berne, Switzerland, were chosen as test cases. We discuss different grid interpolating techniques, other preliminary work and the accuracy of the used LiDAR data and volume estimates.
\end{abstract}

\section{Introduction}

Mountain catchment areas are frequently exposed to erosion and deposition processes, mainly concentrated at steep stream channels (torrents) during runoff events. In alpine torrents mostly sediment laden floods and debris flows, triggered by precipitation events, snowmelt or dam-break failures are reasons for overbank sedimentation or debris deposition. If such gravity-driven mass movements occur, they can have devastating consequences on people, infrastructures and landscape. Both fluvial sediment processes and debris flows can occur at the same time within the same catchment area, possibly interacting with each other. According to Costa (1984) and Hooke and Rohrer (1967) the irreversible sediment entrainment separates debris flows from fluvial sedi-

Correspondence to: C. Scheidl

(christian.scheidl@boku.ac.at) ment transport; the latter can vary their sediment load readily by deposition and erosion, but a debris flow cannot selectively deposit any but the coarsest particles. The emphasis of a hazard assessment for debris flows lays therefore mainly on the deposition cone. Many equations for the estimation of the flow and runout characteristics of debris flows are based on the estimation of the potential volume (e.g. Ikeya, 1989; Iverson et al., 1998; Mizuyama et al., 1992; Rickenmann, 1999; Scheidegger, 1973; Takahashi et al., 1994).

Typically it is recommended that a geomorphologic assessment of the material likely to be mobilised may be the best approach if one intends to arrive at a more precise estimate of a possible debris flow volume (Rickenmann, 1999). Based on unknown previous topography and seldom sufficiently dissected cross-sections of young landslide deposits, Legros (2002) reported that the estimation of debris flow volumes is still difficult. The use of airborne remote sensing methods is therefore a possible way to improve the determination of geomorphometric data in addition to existing event documentations.

For many of the remote sensing applications the data is used to derive an appropriate digital elevation model. The emphasis of this study lies on analyses of LiDAR data. Marchi et al. (2006) list some applications of airborne LiDAR technology in the field of geo-hydrological hazards. Cavalli and Marchi (2008) used LiDAR data to examine the morphology of the alluvial fan of a small alpine stream (Moscardo Torrent, Eastern Italian Alps). Using airborne LiDAR, Woolard and Colby (2002) as well as White and Wang (2003) analysed the morphologic changes of coastlines by analysing two elevation models covering the same area but differing in their time of survey. Applying the same technique to debris flows, a rough estimation of eroded and deposited material can be given. The mass displacement may be calculated by comparing two terrain models representing the situation before and after the event. 


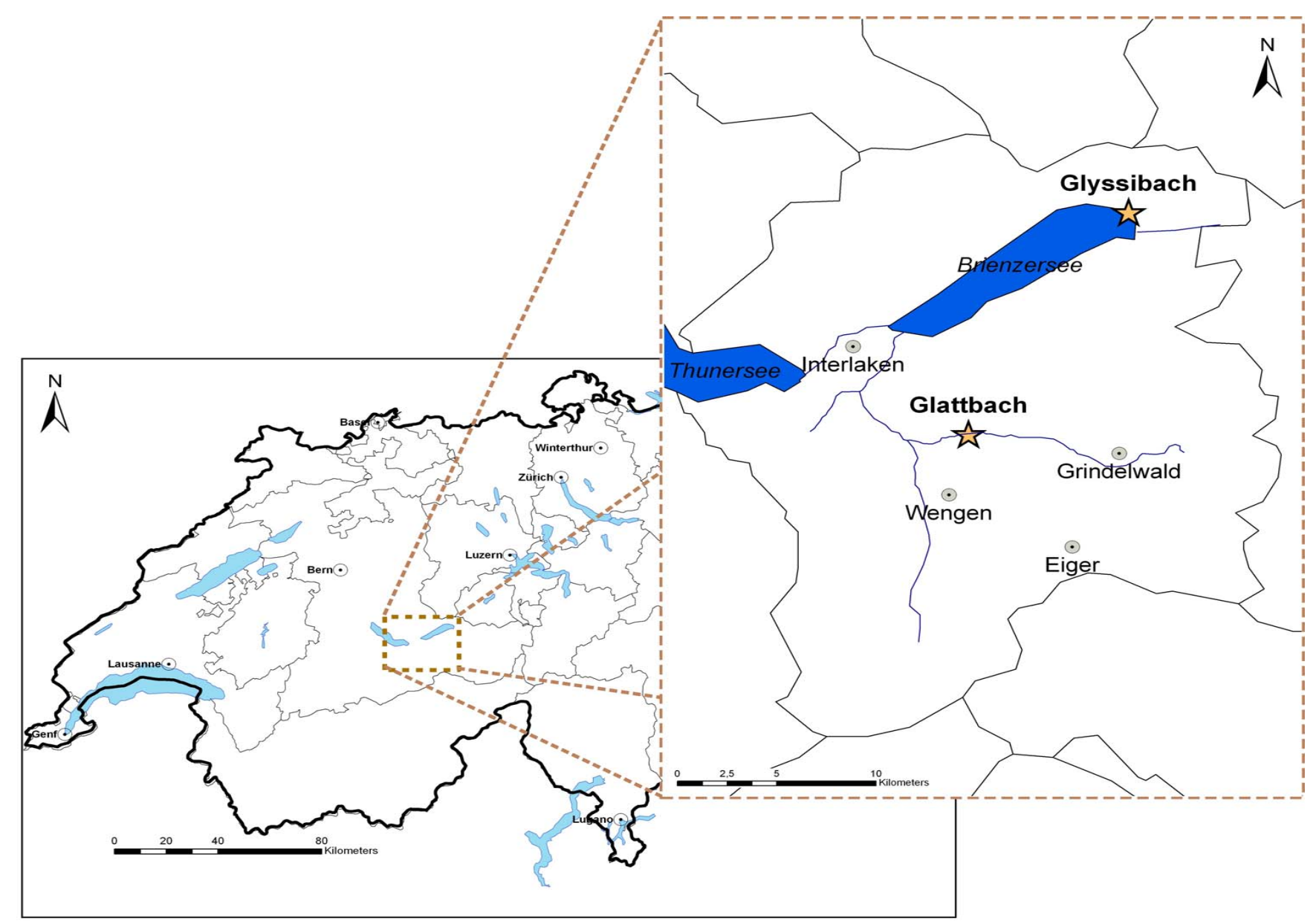

Fig. 1. Location map of the study area. The stars (汴) indicates the field sites.

The objective of this paper is to give an overview on the use of LiDAR data in order to derive a volumetric sediment budget of debris flows by subtracting digital elevation models. A methodology of the necessary preliminary work, identifying the accuracy of the used LiDAR data, is described. The method is applied to two well documented debris flow events in the Swiss Alps and the results are compared. Finally the practicability of LiDAR generated elevation models and its geomorphologic adaptability is discussed.

\section{The debris flow events at Glyssibach and Glattbach 2005 in Switzerland}

Triggered by a heavy precipitation event over the Northern Alps, the flood event of 21-22 August 2005 affected mainly central Switzerland but also parts of Austria and SouthGermany. The total amount of precipitation exceeded on average $100 \mathrm{~mm}$, in some areas even $200 \mathrm{~mm}$ within $48 \mathrm{~h}$, causing floods, fluvial sediment transport processes, landslides and debris flows (Bezzola and Hegg, 2007). Altogether 25 torrent catchments were affected by large debris flow events (Rickenmann et al., 2007). For this study the torrent catchment areas of Glyssibach and Glattbach were selected. The selection criteria were mainly the availability of the existing data respectively general information and the fact that nearly all transported material had to be deposited on the fan area. Both debris flow events vary in their size of deposited volume, however the shape of the deposited area is similar. The deposited material of both events covered a symmetrical area, characterised by a well-defined starting point of channel overtopping. Figure 1 shows the situation of the study area.

The Glyssibach torrent dewaters directly into the lake of Brienz passing the village of Brienz (canton of Berne) on the alluvial cone. The catchment area of the Glyssibach torrent is about $2.2 \mathrm{~km}^{2}$ with an average inclination (catchment) of $24^{\circ}$. During the night from 22 to 23 August 2005, the village was hit by a debris flow triggered by a landslide from the upper Glyssibach catchment. The volume of the deposited debris reached 50000 to $80000 \mathrm{~m}^{3}$ consisting 


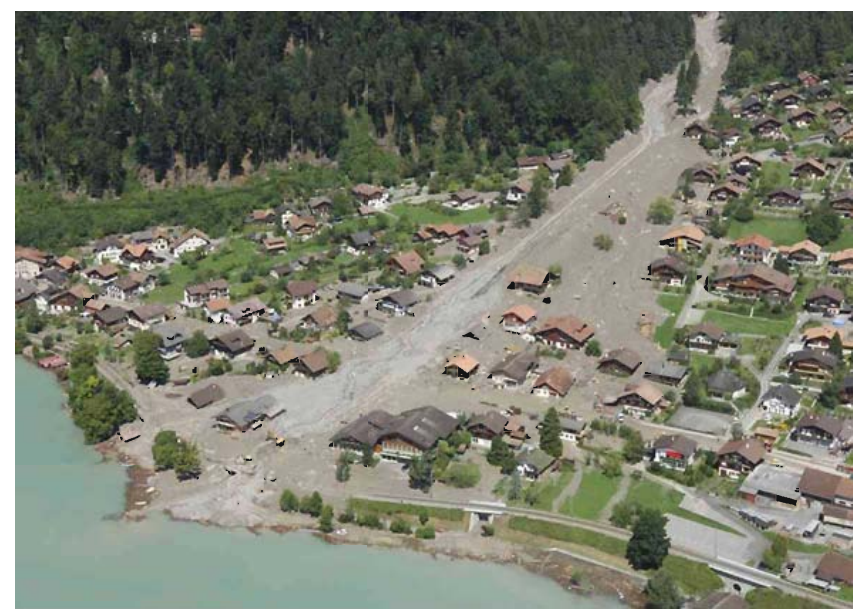

Fig. 2. Deposition cone at Brienz (Glyssibach). Aerial image by Swiss Air Force, August 2005.

mainly of fine-grained material and bigger blocks. The average discharge of the debris flow was about $80 \mathrm{~m}^{3} / \mathrm{s}$ with a peak discharge of about $140-160 \mathrm{~m}^{3} / \mathrm{s}$. Due to a sudden decrease of the channel slope the debris flow started to deposit and spread over the village of Brienz deposited material down to the lake (Fig. 2). The whole deposit covered an area of about $45000 \mathrm{~m}^{2}$ (NDR Consulting Zimmermann/Niederer und Pozzi Umwelt AG, 2006). The documentation of the affected deposition area is based on aerial photogrammetric analysis combined with photographic information as well as on-site field surveying. The deposited material on the fan was determined by a mass-balance assessment along the active stream, combined with a visual inspection of the deposition cone.

The Glattbach torrent acts as a tributary to the "Schwarze Lütschine" belonging to the community of "Lütschental" (canton of Berne). On 22 August 2005, the torrent of the Glattbach showed an increase of the discharge, caused by heavy rainfall during the last two days. The deposition of the eroded material started due to log jams beneath the fan apex. Reaching a volume of the deposited debris of approximately $4000-7000 \mathrm{~m}^{3}$, an area of about $30000 \mathrm{~m}^{2}$ was covered by debris material (Gertsch and Kienholz, 2005).

In Fig. 3, the deposition area of the Glattbach debris flow event is shown. The size of the catchment area of the Glattbach torrent is $1.9 \mathrm{~km}^{2}$ with an average slope inclination of $40^{\circ}$. For this event the affected deposition area was estimated by on-site surveying and field mapping combined with photographic information. The deposited volume was defined by a mass-balance assessment along the active stream.

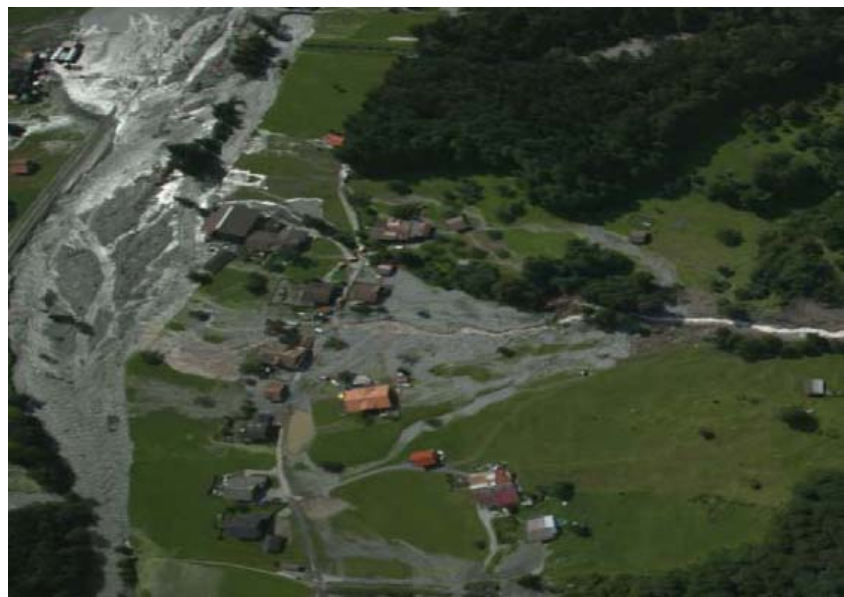

Fig. 3. Deposition cone of Glattbach torrent. Aerial image by Swiss Air Force, August 2005.

\section{Methodology}

LiDAR (light detection and range), like radar, is an active remote sensing technique used for an extensive and contactless survey of the earth's surface. A modern LiDAR acquisition begins with a "photogrammetric aircraft" equipped with Airborne GPS (for $x, y, z$ sensor location), an inertial measuring unit (for measuring the angular orientation of the sensor with respect to the ground), a rapidly pulsing (20000 to 50000 pulses/s) laser, a highly accurate clock, substantial onboard computer support, reliable electronics, and robust data storage (Lillesand et al., 2004).

Within the last years, particularly an improvement of the laser pulse rate (up to 133000 pulses/s) and an increase in the accessible operation altitude, could be observed. Table 1 indicates some recent specifications of commonly used laser scanning systems. The physical measuring procedure of a $\mathrm{Li}$ DAR apparatus is based on a laser beam scanning a defined range of the landscape. This range mainly depends on the flight altitude and the position of the aeroplane (pitch). Due to overlapping effects the surveyed area will be scanned several times. The most exact points are to be filtered for further processing.

Landtwing (2005) developed a method to visualise the particularities of LiDAR points to support such filtering routines. The so obtained scatter set of echo points carries only geometrical and no semantic information. To distinguish between an elevation model covering the surface of the surveyed area from the bare earth ground beneath, one has to classify the scanned scatter set by using again filteralgorithms (Axelsson, 2000; Kraus, 1997; Kraus and Pfeifer, 2001; Vosselman, 2000). For commercial use a distinction is made between first echo points - reflecting the scanned earth surface - and last echo points - representing to the scanned bare-earth ground. The elevation model interpolated from 
Table 1. Technical details of some used laser systems in Europe (Optech, 2008; TopoSys, 2007).

\begin{tabular}{llllll}
\hline Laser System & ALTM 3100 & Falcon II & Falcon III & Harrier 56 & Harrier 24 \\
\hline Operation altitude & $80-3500 \mathrm{~m}$ & $1600 \mathrm{~m}$ & $30-2500 \mathrm{~m}$ & $30-1660 \mathrm{~m}$ & $10-563 \mathrm{~m}$ \\
Laser repetition rate & $33-100 \mathrm{kHz}$ & $83 \mathrm{kHz}$ & $50-125 \mathrm{kHz}$ & $100 / 133 \mathrm{kHz}$ & $10 \mathrm{kHz}$ \\
Scan frequency & variable, max. $70 \mathrm{~Hz}$ & $653 \mathrm{~Hz}$ & $165-415 \mathrm{~Hz}$ & $5-160 \mathrm{~Hz}$ & $6-80 \mathrm{~Hz}$ \\
Field of view & 50 & 21.6 & 30 & 45 & 60 \\
Range capture & up to 4 per pulse & first echo, last echo, intensity & up to 9 per pulse & full waveform \\
Constructor & Optech Inc. & TopoSys & TopoSys echo, last echo & TopoSys & TopoSys \\
\hline
\end{tabular}

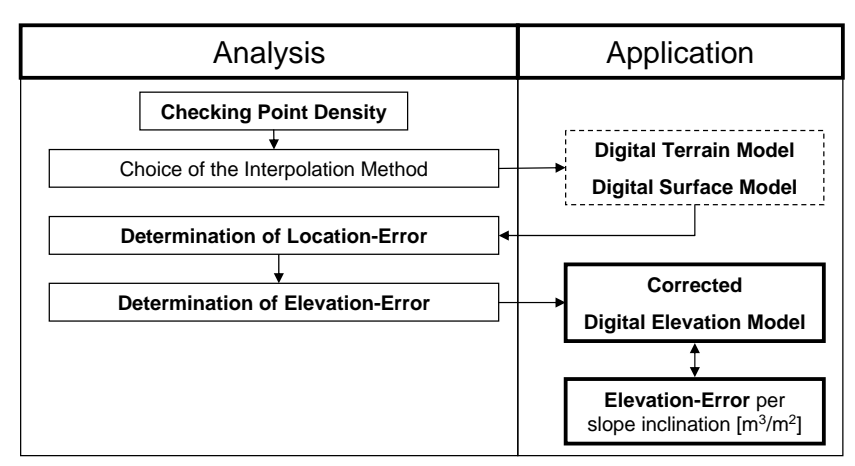

Fig. 4. Applied analysing steps of raw LiDAR data within this study.

a first echo scatter set is defined as digital surface model (DSM). The elevation model generated from last echo points is called digital terrain model (DTM).

The raw datasets used in this study consist of first-echo sets of LiDAR points (surface models), reflecting the scanned earth surface (including vegetation, houses,...) as well as already filtered last-echo sets of LiDAR points (terrain models), representing the bare earth-ground. We assume that this kind of supplied data represents the most frequent use of commercial LiDAR data.

\subsection{LiDAR - analysis}

Changes of the geomorphology in torrents after an event can be described by comparing elevation models covering the same area but differing in their time of survey. The deviations between deposited or eroded volumes determined from commercial LiDAR data and actually deposited or eroded material in nature can be attributed mainly to following error sources:

\section{- Density-error}

For the generation of elevation models the density of the scanned points is an important quality index. Due to the fact that the penetration rate depends on the surface type, the density of the scanned points per area is not homogeneous over the whole surveyed landscape.

\section{- Device-errors}

These are technical, "physical" errors of the measuring apparatus. The magnitude of the error depends on the kind of the construction, on adjusting errors or wellknown error tolerances.

\section{- Measurement-errors}

These errors are due to environmental parameters, which directly influence the measurements. For LiDAR data this concerns particularly meteorological conditions during the flight (weather, wind, flight altitude...).

\section{- Data-processing-errors}

These errors are induced by data filtering methods only affecting digital terrain models (DTM).

Information about geomorphologic changes (erosion or deposition) result from subtraction of two elevation models. The error of the analysed volumes depends on the error of the DEMs and thus on the errors described above. Usually commercially obtained LiDAR data consist of X, Y, Z scatter-sets with 3 possible error types:

- $F_{x}$ error of X-value (Easting)

- $F_{y}$ error of Y-value (Northing)

- $F_{H}$ error of Z-value (Altitude)

Due to the dependency between elevation and location in space we summarised the errors of the $\mathrm{X}$ - and Y-values, leading to a location- $\left(F_{L}\right)$ and elevation-error $\left(F_{H}\right)$. The determination of $F_{L}$ and $F_{H}$ serves as a plausibility check for any data comparison. $F_{L}$ respectively $F_{H}$ are defined as the difference of the measured value $\left(\delta_{M}\right)$ with the well-known value $\left(\delta_{T}\right)$ in nature:

$F=\delta_{M}-\delta_{T}$

The well-known value in nature, or also "true" value, is typically determined by means of terrestrial measured control points (house corners, crossovers, stones, etc.). Furthermore the accuracy of the calculated volume is directly related to the density of the surveyed LiDAR points.

For our data sets we estimated the possible errors before using them to analyse geomorphological changes. The applied steps of analysis are shown in Fig. 4. 


\subsubsection{Point density}

A rapid statement about the quality of the LiDAR data can be made by a visual view of the point distribution related to the surveyed area. The density variation of first echo points are mostly due to measuring losses. Here free water surfaces, which do not cause any reflection of the incoming laser beam have to be mentioned. A lower spatial density of the last echo points is particularly caused by natural measuring obstacles, as they occur for instance on dense forest areas. The laser beam cannot penetrate so easily any longer to the earths surface (see Fig. 5).

James et al. (2007) and Cavalli et al. (2008) showed that the point density plays a decisive role when analysing mountain catchments. Nevertheless LiDAR normally enables point sampling at very small separation distances (high density), but still subsequent prediction from points to a grid is subject to considerable uncertainty (Lloyd and Atkinson, 2002).

A statement about the precision of the calculated volume is therefore related to the selected grid interpolating techniques.

\section{Data and error analysis}

The principal data to determine geomorphological modifications is elevation information in space. Such information can be obtained by several remote and terrestrial sensing techniques. The emphasis of this study is on LiDAR data, which were used to generate digital elevation models (DEM) of the interested areas. Elevation models generated from airborne remote data correspond to the geomorphologic features of the earth's surface at the time of the flight.

\subsection{Dataset}

The dataset for this study is based on elevation data from airborne LiDAR investigations. The following datasets were available for the analysis of the morphologic changes of the Glyssibach and Glattbach debris flow events.

\section{Before the event 2005:}

With commission of the Swiss Federal Office of Topography (swisstopo), the Swissphoto Group AG accomplished LiDAR flights over large areas of Switzerland from 2000 to 2006. Except for the cantons Obwalden and Nidwalden LiDAR data were obtained for entire Switzerland up to an elevation of $2000 \mathrm{~m}$ a.s.l. The areas of interest, affected by the flood event 2005 , were surveyed by LiDAR flights between the years 2001 and 2003. The type of sensor used was an ALTM 3100. Technical features of the ALTM system are listed in Table 1. The datasets before the event consist of first- and last echo LiDAR points of the deposition area of the Glattbach and of the total reach of the Glyssibach torrent.
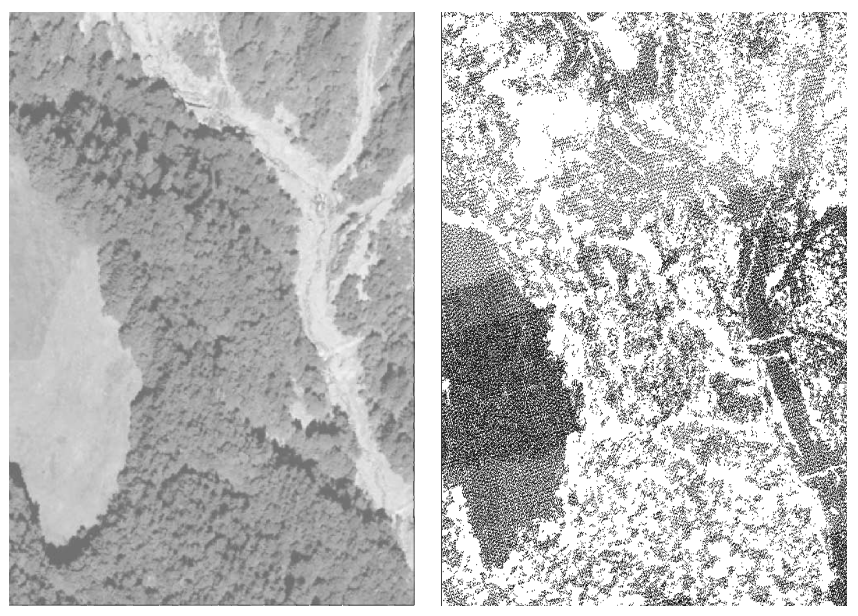

Fig. 5. Example of density variation of LiDAR points due to forest areas.

After the event 2005:

After the flood event 2005, the company Toposys GmbH Germany (Toposys) accomplished LiDAR flights on behalf of the Swiss Federal Office for the Environment (BAFU) over selected areas of the canton Berne (Häberli, 2006) including the Glyssibach and the Glattbach fan area. Again the dataset consists of first- and last echo LiDAR points for the two debris flow events. Based on the same LiDAR points, elevation models generated by the company Toposys were additionally provided for each event. Comparing the elevation model of Toposys with the elevation model generated from the LiDAR points, we noticed no difference in location but a difference in elevation information. Within this study both digital terrain models are therefore used and evaluated. The used sensor type was a Falcon II (see Table 1 for technical details).

For each event four scatter sets of LiDAR scanned points and two digital terrain models were acquired. Tables 2 and 3 show an overview of the available datasets within this study.

4.2 Determination of the relative location- $\left(F_{L}\right)$ and elevation-error $\left(F_{H}\right)$

Given that no terrestrial control points have been surveyed after the flood event 2005, points of equal locations (pseudocontrol points) were defined when looking at the elevation models before and after 2005. Therefore $F_{L}$ and $F_{H}$ are treated as relative-errors and the following assumptions are made:

- Pseudo control points can only be determined on the basis of surface models (DSM) where objects like house edges, roof ridges, road crossings, forks, etc., can be identified. 
Table 2. Overview about the used dataset of Glyssibach; DSM(LiDAR): digital surface model generated from first echo points; DSM(Toposys) digital surface model obtained from Toposys; DTM(LiDAR): digital terrain model generated from last echo points; DTM(Toposys) digital terrain model obtained from Toposys.

\begin{tabular}{lcccc}
\hline & $\begin{array}{c}\text { DSM }_{\text {LiDAR }} \\
\text { Glyssibach }\end{array}$ & $\begin{array}{c}\text { DSM }_{\text {Toposys }} \\
\text { Glyssibach }\end{array}$ & $\begin{array}{c}\text { DTM } \\
\text { GiDAR } \\
\text { Glyssibach }\end{array}$ & $\begin{array}{c}\text { DTM Toposys } \\
\text { Glyssibach }\end{array}$ \\
\hline $\begin{array}{l}\text { before 2005 } \\
\text { after 2005 }\end{array}$ & $\mathrm{Gly}_{b}$ & - & $\mathrm{Gly}_{b}$ & - \\
\hline & $\mathrm{Gly}_{a}$ & ${\text { Gly } \operatorname{STopo}_{a}}$ & $\mathrm{Gly}_{a}$ & GlyTTopo $_{a}$ \\
\hline
\end{tabular}

- Pseudo control points of the pre-event surveyed surface model are treated as well-known values in nature.

- Pseudo control points must be set randomly within the entire range of the considered surface model, which is not always possible due to the lack of clearly identifiable objects in some areas.

- Pseudo control points may only be set in areas with no expected changes between two related LiDAR surveys.

- The determination of the relative location- and elevation error is carried by intercept the pseudo control points with the related digital terrain models (DTM).

With the pseudo control point before the event $\delta_{A}=\left(A_{x} \mid A_{y}\right)$ and the related pseudo control point after the event $\delta_{B}=\left(B_{x} \mid B_{y}\right)$ the location error results in

$F_{L}=\left\{\begin{array}{l}F_{L x} \\ F_{L y}\end{array}\right\}=\left\{\begin{array}{l}A_{x} \\ A_{y}\end{array}\right\}-\left\{\begin{array}{l}B_{x} \\ B_{y}\end{array}\right\}$

and the mean location-error can be calculated as

$\bar{F}_{L}=\sum_{i=1}^{n} \frac{1}{n}\left[\left(A_{x i}-B_{x i}\right)-\left(A_{y i}-B_{y i}\right)\right]$.

The same procedure can be applied to estimate a relative elevation-error $F_{H}$.

Since pseudo control points are determined on the basis of elevation models, the minimum location-error directly depends on the mesh size of the surface grids. Therefore the minimum location error for a given mesh size $(n)$ can be calculated (assuming a rectangular grid base):

$F_{x_{\min }}=F_{y_{\min }}=n \Rightarrow F_{L_{\min }}=\sqrt{2 n^{2}}$.

Only if $\bar{F}_{L}>F_{L_{\min }}$, a systematic mean location-error can be determined. However, the location error $F_{L}$ as well as the elevation error $F_{H}$ have to be considered and the digital terrain models (DTM) generated from LiDAR data after the event have to be corrected before proceeding the next step.
Table 3. Overview about the used dataset of Glattbach; DSM(LiDAR): digital surface model generated from first echo points; DSM(Toposys) digital surface model obtained from Toposys; DTM(LiDAR): digital terrain model generated from last echo points; DTM(Toposys) digital terrain model obtained from Toposys.

\begin{tabular}{lcccc}
\hline & $\begin{array}{c}\text { DSM }_{\text {LiDAR }} \\
\text { Glattbach }\end{array}$ & $\begin{array}{c}\text { DSM }_{\text {Toposys }} \\
\text { Glattbach }\end{array}$ & $\begin{array}{c}\text { DTM }_{\text {LiDAR }} \\
\text { Glattbach }\end{array}$ & $\begin{array}{c}\text { DTM }_{\text {Toposys }} \\
\text { Glattbach }\end{array}$ \\
\hline $\begin{array}{l}\text { before 2005 } \\
\text { after 2005 }\end{array}$ & $\mathrm{Gla}_{b}$ & - & $\mathrm{Gla}_{b}$ & - \\
$\mathrm{Gla}_{a}$ & $\mathrm{GlaSTopo}_{a}$ & $\mathrm{Gla}_{a}$ & GlaTTopo $_{a}$ \\
\hline
\end{tabular}

\subsection{Spatial distribution of $F_{L}$ and $F_{H}$}

The spatial distribution of the location and elevation error of all measured control points gives an overview of the relative accuracy of the two elevation models. If all control points are distributed homogeneously over the whole surface, a trend of a wavy surface of the elevation differences could be detected. Companies providing LiDAR data try to avoid this phenomenon by using so called pass-points (points of geographical reference information) defined by the costumer (S. Kurz: Topographische Systemdaten GmbH, personal communication 28 February 2008, 2008). After the scan a correction of the LiDAR data is done, based on these pass-points to avoid wavy misalignment between elevation models.

For our investigated areas the limiting factor for the determination of the location-error lies in an adequate identification of the pseudo control points. For example, Fig. 6 displays the pseudo control points and their spatial distribution of the elevation errors for the deposition area of the Glattbach torrent. Although a slight tilting can be observed, it cannot be excluded that this effect may result from the small number of determined pseudo control points related to the considered surface. For this study a simplified correction is made assuming a spatial constant elevation error.

If there are not sufficient identifiable items such as houses, roads, etc., distributed over the whole surface, the relative location-error respectively elevation-error cannot be estimated.

4.4 Determination of $F_{H}$ as a function of the slope inclination

In areas with (relatively) flat topography the elevation-error can be kept small due to minimising the relative elevationerror as described before. In steeper areas the elevationerror increases proportionally to the location-error. Using LiDAR generated Level2-USGS digital elevation models, Hodgson et al. (2003) found a significant relationship between the mean absolute elevation error and increasing slope. This means that the elevation-error does not only depend on 


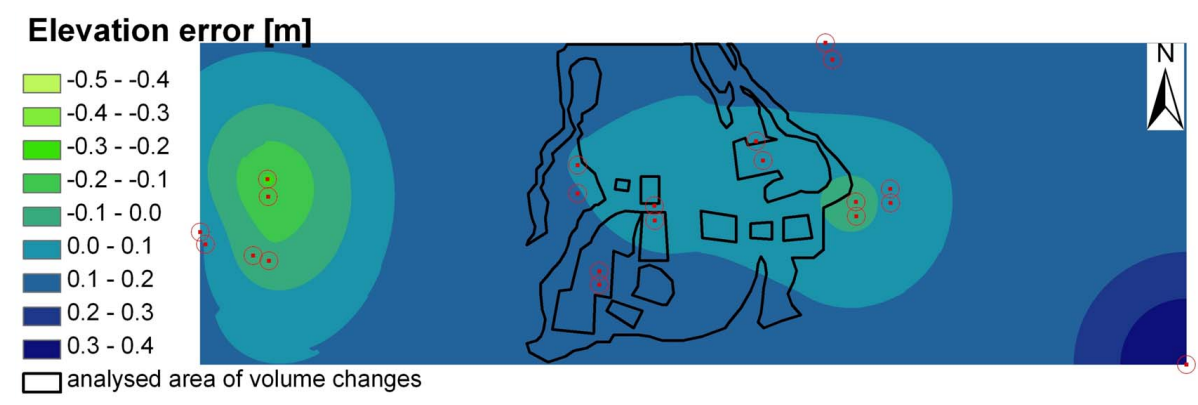

Fig. 6. Example of spatial distribution of the elevation errors for the deposition area of Glattbach.The red dots indicate the location of the pseudo control points.

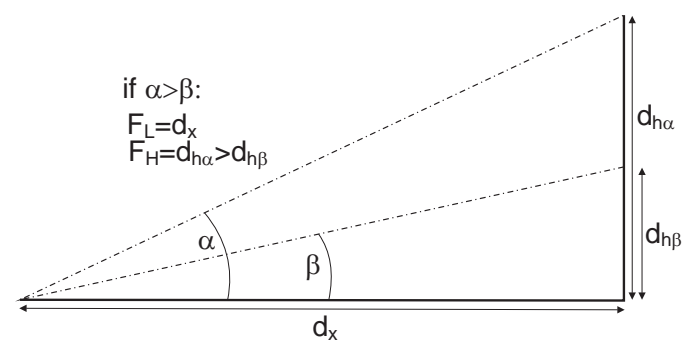

Fig. 7. Location- and elevation-error in relation to the slope inclination.

the relative location error but also on the slope inclination (Fig. 7).

It is important to know the maximum possible range of the elevation-error as a function of the slope inclination when analysing volumetric changes between two elevation models. For this purpose we only consider areas without evident geomorphologic changes before and after the event, using digital terrain models of the test sites with a $1 \times 1 \mathrm{~m}$ grid resolution. The spatial distribution of the elevation differences is computed by subtracting the digital elevation model after the event with the digital elevation model before the event. A so called differential grid (Fig. 8) can be generated, showing areas with a positive and negative error in elevation.

In a further step slope inclination classes are defined for the area of interest. Their spatial distribution leads to a new grid designated as slope grid. By clipping the differential grid with the slope grid, information about elevation-error per inclination class can be obtained. This new map gives a spatial overview of the possible errors in volume estimation. Regions with higher errors can easily be identified for further analyse decisions. To quantify the elevation-error per slope inclination class $\left[\mathrm{m}^{3} / \mathrm{m}^{2}\right]$, we average elevation differences over the corresponding area.

The correlation between elevation-error and slope inclination is illustrated as an example for 6 torrent catchment areas in the canton of Berne (Fig. 9). In general, the elevation-error

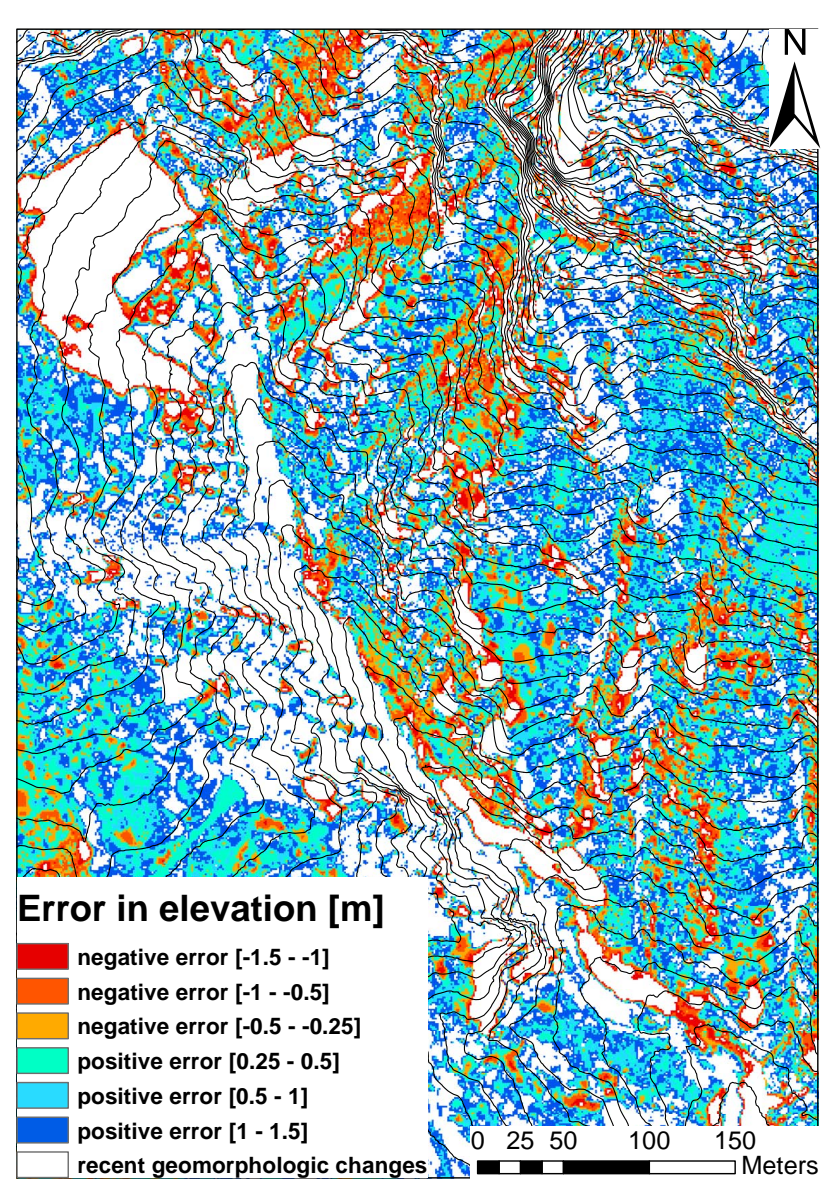

Fig. 8. Differential grid (Glyssibach); The white range reflects areas with recent geomorphologic changes.

is seen to increase for slope inclination larger than approximately $25^{\circ}$. Figure 9 also shows that an elevation error in flat areas $F_{H}$ has to be considered. 


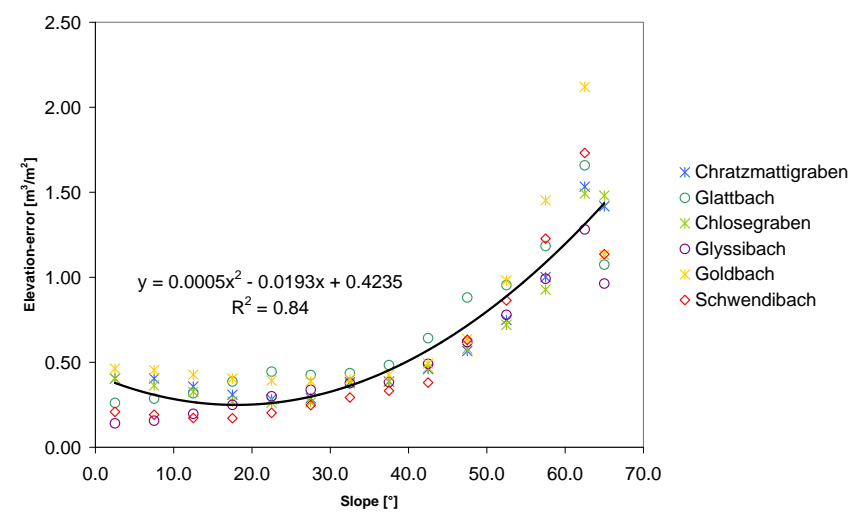

Fig. 9. Correlation between elevation-error and slope inclination for selected catchment areas of the canton Berne.

Table 4. Percentage of original data points (cluster 1-3) used for generating (group A) and testing (group B) elevation values.

\begin{tabular}{lccc}
\hline & cluster 1 & cluster 2 & cluster 3 \\
\hline group A & $50 \%$ & $25 \%$ & $5 \%$ \\
group B & $50 \%$ & $50 \%$ & $50 \%$ \\
\hline
\end{tabular}

\section{Application, data pre-processing}

\subsection{Point density and interpolation techniques applied}

Within this study LiDAR data were obtained on a point basis which made it necessary to interpolate them to a regular grid in order to generate digital elevation models. Crossvalidation and a methodology characterised as "jack-knife" process, was used to provide a basic comparison of three common interpolation techniques, namely inverse distance weighted (IDW), natural neighbourhood (NN) and universal kriging (UK). For the techniques IDW and UK a fixed search radius of $15 \mathrm{~m}$ with a range of $1-15$ neighbours (data points) has been chosen. A power value of 4 was selected for the IDW technique, describing a higher influence of the nearest data points. Similar no nugget-effect of the UK technique was applied. For the NN interpolation technique, no parameters needed to be selected. By using descriptive statistical methods (mean error, standard deviation) the best fit interpolation technique was then selected.

Initially the data sets were divided randomly into 3 clusters of respectively 2 groups (Table 4 ) whereas $\overline{B 1}=\overline{B 2}=\overline{B 3}$. The first cluster consisted of two equal groups. The first half $(\overline{A 1})$ was used to predict the elevation at the location of the other group $(\overline{B 1})$ by generating an elevation model adopting the three interpolation techniques. The same procedure was repeated for the two other clusters, using $25 \%(\overline{A 2})$ and only $5 \%(\overline{A 3})$ of the data for spatial prediction of $\overline{B 2}$ respectively
Table 5. Average point density of the Glyssibach elevation models to compare different interpolation methods within this study.

\begin{tabular}{ll}
\hline $\begin{array}{l}\% \text { of original data } \\
\text { points used for gen- } \\
\text { erating elevation } \\
\text { model }\end{array}$ & $\begin{array}{l}\text { average point den- } \\
\text { sity }\left[\text { point } / \mathrm{m}^{2}\right]\end{array}$ \\
\hline 50 & 0.43 \\
25 & 0.22 \\
5 & 0.04 \\
\hline
\end{tabular}

Table 6. Average point density of the Glattbach elevation models to compare different interpolation methods within this study.

\begin{tabular}{ll}
\hline $\begin{array}{l}\% \text { of original data } \\
\text { points used for gen- } \\
\text { erating elevation } \\
\text { model }\end{array}$ & $\begin{array}{l}\text { average point den- } \\
\text { sity [point } / \mathrm{m}^{2} \text { ] }\end{array}$ \\
\hline 50 & 0.81 \\
25 & 0.38 \\
5 & 0.08 \\
\hline
\end{tabular}

$\overline{B 3}$. The extracted data were then used to assess the accuracy of the predictions.

This methodology was applied on selected regions within the deposition areas of Glyssibach and Glattbach. For each region a scatter set of last echo points, before and after the event 2005, were used to generate a digital terrain model. Tables 5 and 6 give an overview about the basic settings for the test areas of Glyssibach and Glattbach.

The average errors and their standard deviations of estimates were calculated, using $50 \%, 25 \%$ and $5 \%$ of the data, and are shown in Figs. 10 and 11. For both tested areas the interpolation method of IDW differs clearly from the two other proposed techniques, UK and NN. We therefore postulate that IDW is not an adequate interpolation technique for our dataset. Further it is obvious that the standard deviation decreases as the number of points, used for elevation modelling, increases - whereas the average prediction error remains constant. It appears that for our dataset even for a small average point density the interpolation techniques UK and NN are similar. So we chose Natural Neighbour (NN) as an adequate interpolation technique for our dataset due to its simplicity and fast realisation. By reason of an average point density (of the entire LiDAR data) greater than 1 point $/ \mathrm{m}^{2}$ we adopted the mesh size of the elevation models to $1 \mathrm{~m}(n=1 \mathrm{~m})$. The scatter sets of last- respectively first-echo points of both regions, Glyssibach and Glattbach, were then used to generate four elevation models before, Gly $S_{b}$, Gly $T_{b}$, $\mathrm{Gla}_{b}, \mathrm{Gla}_{b}$, and four elevation models after the event of 2005, Gly $S_{a}$, Gly $T_{a}, \mathrm{Gla}_{a}, \mathrm{GlaT}_{a}$ (see also Tables 2 and 3). 


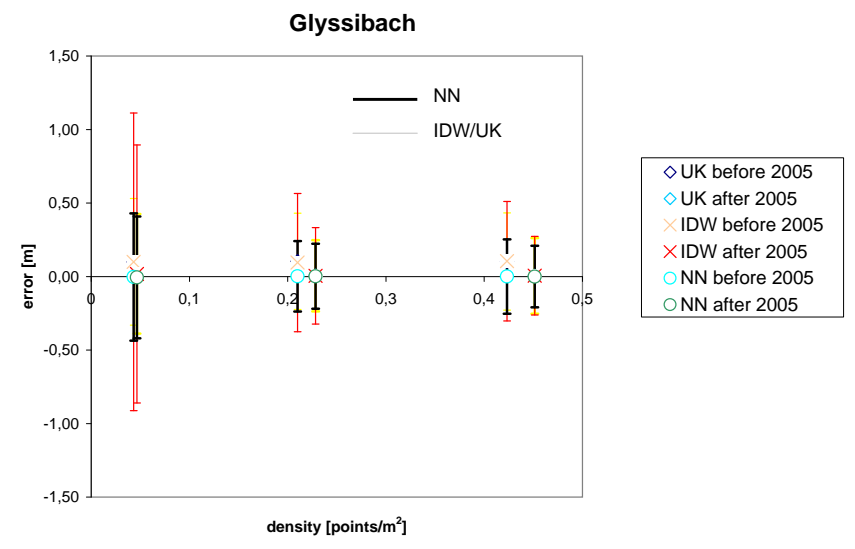

Fig. 10. Error estimates using different interpolation techniques for the test-area Glyssibach.

Table 7. Average point density of the active areas for the analysis of the debris flow event Glyssibach.

\begin{tabular}{lccc}
\hline $\begin{array}{l}\text { active } \\
\text { area }\end{array}$ & $\begin{array}{c}\mathrm{Gly}_{b} \\
{\left[\text { points } / \mathrm{m}^{2}\right]}\end{array}$ & $\begin{array}{c}\mathrm{Gly}_{a} \\
{\left[\text { points } / \mathrm{m}^{2}\right]}\end{array}$ & $\begin{array}{c}\text { GlyTTopo }_{a} \\
{\left[\text { points } / \mathrm{m}^{2}\right]}\end{array}$ \\
\hline $\begin{array}{c}\text { landslide } \\
\text { (Baalen) }\end{array}$ & 0.89 & 1.19 & - \\
active reach & 0.78 & 1.37 & - \\
\hline
\end{tabular}

5.2 Determination of the location- and elevation-error for the dataset of Glyssibach

Both, LIDAR point and Toposys generated elevation models before and after the event (see Table 2) cover the entire range of the debris flow of 2005 in the Glyssibach. Since most of the deposition occured primarily within the village of Brienz (Fig. 2), much debris material was removed before the LiDAR scan. Therefore a sediment budget was established only for torrent reaches upstream of the fan. The estimated sediment volume passing the fan apex is thus treated as potential deposit volume. The loss of material due to sediment input and deposition into the lake of Brienz is supposed to be very small and was therefore neglected. An overview of the average point density of the used elevation models for the active areas can be seen in Table 7. The effective point density for the Topogrid generated elevation models could not be specified (see also Sect. 4.1).

For the identification of the local-error, 37 pseudo-control points were defined on the surface model before the event $\left(\mathrm{Gly} S_{b}\right)$ and on the surface models after the event (Gly $S_{a}$ and Gly $S \mathrm{Topo}_{a}$ ). Table 8 shows the average values of the relative errors between the digital terrain models before and after the event of Glyssibach. For the dataset Gly $T_{a}$ and GlyT Topo $_{a}$ no difference in location could be detected. The
Table 8. Computed location and elevation errors for the surveyed area of Glyssibach.

\begin{tabular}{lccccc}
\hline & $\mathrm{N}$ & $\begin{array}{c}\text { min. } \\
\text { value }[\mathrm{m}]\end{array}$ & $\begin{array}{c}\text { max. } \\
\text { value }[\mathrm{m}]\end{array}$ & $\begin{array}{c}\text { mean } \\
\text { value }[\mathrm{m}]\end{array}$ & $\begin{array}{c}\text { standard } \\
\text { deviation }[\mathrm{m}]\end{array}$ \\
\hline$F_{x}$ & 37 & -0.92 & 1.47 & 0.18 & 0.64 \\
$F_{y}$ & 37 & -3.29 & 1.20 & -0.25 & 0.84 \\
$F_{L}$ & 37 & -0.95 & 1.23 & 0.11 & 0.56 \\
$F_{H G l y T_{a}}$ & 37 & -2.13 & 1.94 & 0.05 & 0.73 \\
$F_{\text {HGlyTTopo }}$ & 37 & -0.52 & 1.78 & 0.17 & 0.52 \\
\hline
\end{tabular}

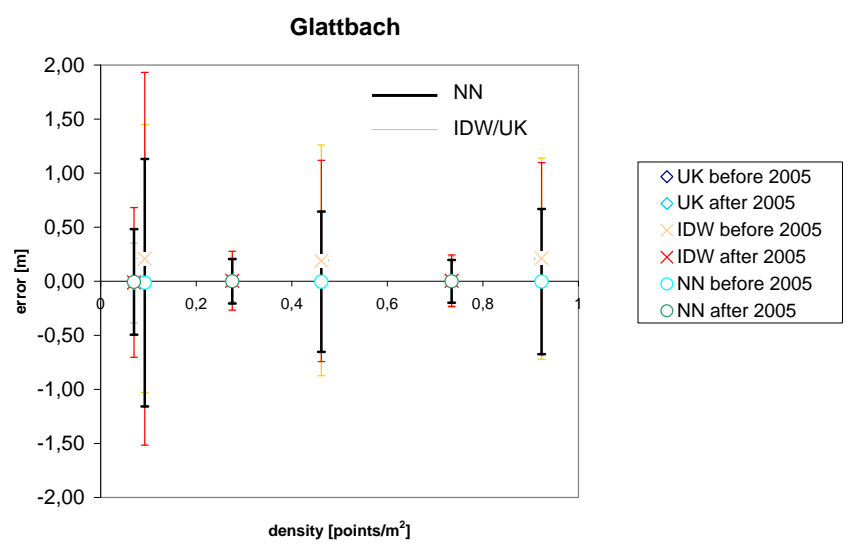

Fig. 11. Error estimates using different interpolation techniques for the test-area Glattbach.

average value of the difference of the location $F_{L}$ is clearly smaller than the mesh size of the surface model,

$F_{L}=0.11 \pm 0.56<\sqrt{2 n^{2}}=1.41 \mathrm{~m} ;$

therefore no systematic location error could be assumed. The average elevation errors, $F_{H \mathrm{Gly} T_{a}}$ and $F_{H \mathrm{GlyTT}_{\mathrm{Topo}}}$ shown in Table 8, represent only flat regions within the surveyed area. Since the deposited sediment volume was analysed due to a sediment budget along the active stream with an average slope of $18^{\circ}$, the average elevation errors were not considered.

In a further step, according to Fig. 4, the distribution of the elevation error as a function of the slope inclination had to be determined.

Figure 12 shows the empirical relations of mean elevation error against slope inclination class using the digital terrain models after the event - either Gly $T_{a}$ or GlyTTopo $a$. In both cases the error distribution is described by a quadratic function with a coefficient of determination $\left(R^{2}\right)$ of $92 \%$ for the elevation model generated from last echo LiDAR points respectively $R^{2}=96 \%$ for the Toposys elevation model.

This empirical relations are used when estimating the volume of eroded and deposited material during the debris-flow event at Glyssibach, 2005. 


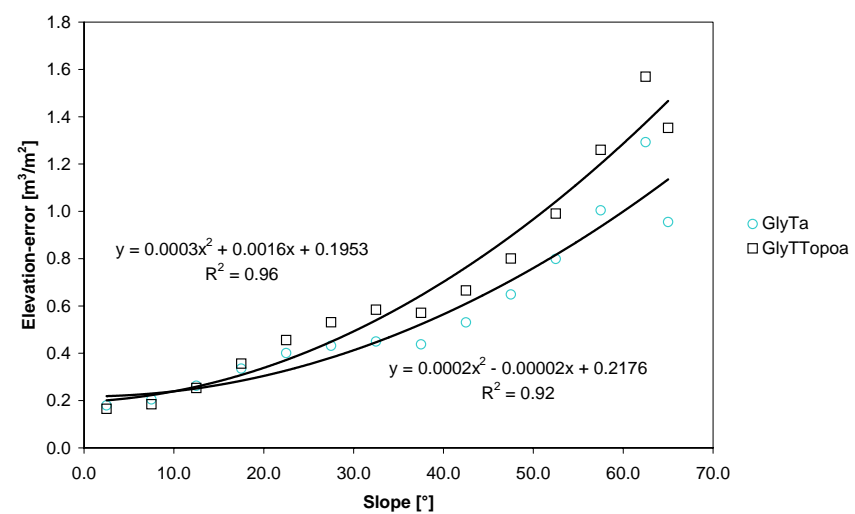

Fig. 12. Correlation between elevation error against slope inclination for the surveyed area of Glyssibach without any correction of the elevation models.

Table 9. Average point density of the active areas for the analysis of the debris flow event Glattbach.

\begin{tabular}{cccc}
\hline active area & $\begin{array}{c}\mathrm{Gla}_{b} \\
{\left[\text { points } / \mathrm{m}^{2}\right]}\end{array}$ & $\begin{array}{c}\mathrm{Gla}_{a} \\
{\left[\text { points } / \mathrm{m}^{2}\right]}\end{array}$ & $\begin{array}{c}\mathrm{GlaTTopo}_{a} \\
{\left[\text { points } / \mathrm{m}^{2}\right]}\end{array}$ \\
\hline fan area & 0.82 & 1.66 & - \\
\hline
\end{tabular}

5.3 Determination of the location- and elevation-error for the dataset of Glattbach

Since the aerial laser survey mainly focused on the valley river "Schwarze Lütschine", only the fan region of the Glattbach torrent was covered by LiDAR data after the flood event 2005. Table 9 shows the average point density of the used elevation models for the fan area. The effective point density of the Topogrid generated elevation models is again unknown (see Sect. 4.1).

23 pseudo-control points were defined using the surface model before the event $\left(\mathrm{Gla}_{b}\right)$ and the surface models after the event $\left(\mathrm{Gla}_{a}\right.$ and $\left.\mathrm{GlaSTopo}_{a}\right)$ for the deposition area of Glattbach. The distribution of the residuals between the control points for the situation before and after the event 2005 yields to the relative location and elevation errors based on the terrain models $\mathrm{Gla}_{a}$ and GlaT Topo ${ }_{a}$, whereas no difference in location could be noticed. Table 10 shows the estimated values of the relative errors between $\mathrm{Gla}_{a}$ and Gla $S_{b}$ respectively GlaSTopo ${ }_{a}$. Again the average value of the difference of the location $F_{L}$ is clearly smaller than the mesh size of the surface model,

$F_{L}=0.23 \pm 0.52<\sqrt{2 n^{2}}=1.41 \mathrm{~m}$

and no systematic location error can be assumed. Here the emphasis of the geomorphologic analyse is based on the surveyed deposition area with an average slope of $8^{\circ}$. Hence

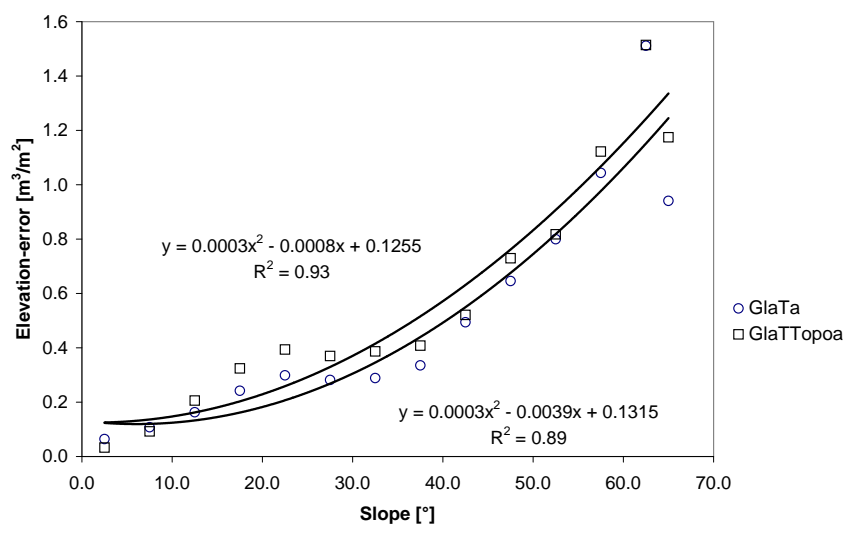

Fig. 13. Correlation between elevation error against slope inclination for the surveyed area of Glattbach after a correction of the elevation models considering $F_{H G l a} T_{a}(0.08 \mathrm{~m})$ and $F_{H G l a T T_{0 p o}}$ $(0.14 \mathrm{~m})$

the elevation models after the event for the Glattbach torrent $\left(\mathrm{Gla}_{a}, \mathrm{GlaTTopo}_{a}\right)$ were corrected with the systematic elevation errors of $0.08 \mathrm{~m}$ and $0.14 \mathrm{~m}$, respectively (see Table 10).

The pseudo-control points were determined in relatively flat areas, which made it necessary to define an empirical relationship between elevation error and slope inclination for the elevation models of Glattbach (Fig. 13). Also for the surveyed area of the Glattbach the error distribution can be described by a quadratic function with a coefficient of determination $\left(R^{2}\right)$ of $89 \%$ for the elevation model generated from last echo LiDAR points respectively $R^{2}=93 \%$ for the Toposys elevation model.

\section{Analysis of geomorphologic parameters of the se- lected debris flow events 2005}

\subsection{Analysis of the debris flow event Glyssibach}

The transferred and deposited material originated on the one hand from a landslide in the upper region of the catchment area (Baalen, $1050 \mathrm{~m}$ ) and on the other hand from strong vertical and/or lateral erosion processes along the channel (Figs. 14 and 15). Regarding the landslide activity at Baalen, the event documentation of Glyssibach (NDR Consulting Zimmermann/Niederer und Pozzi Umwelt AG, 2006) reported about $30000 \mathrm{~m}^{3}$ of eroded material. Further, $35000 \mathrm{~m}^{3}$ to $45000 \mathrm{~m}^{3}$ of net erosion along the channel were estimated. The total amount of deposited material on the fan, reported by the local event documentation was therefore estimated between $50000 \mathrm{~m}^{3}$ and $80000 \mathrm{~m}^{3}$.

Using the elevation models Gly $T_{b}$, Gly $T_{a}$ and GlyT Topo ${ }_{a}$, the areas of the erosion and deposition processes, described by the local event documentation, were analysed with the 
Table 10. Computed location and elevation errors for the surveyed area of Glattbach.

\begin{tabular}{lccccc}
\hline & $\mathrm{N}$ & $\begin{array}{c}\text { min. } \\
\text { value }[\mathrm{m}]\end{array}$ & $\begin{array}{c}\text { max. } \\
\text { value }[\mathrm{m}]\end{array}$ & $\begin{array}{c}\text { mean } \\
\text { value [m] }\end{array}$ & $\begin{array}{c}\text { standard } \\
\text { deviation [m] }\end{array}$ \\
\hline$F_{x}$ & 23 & -0.82 & 1.32 & 0.35 & 0.51 \\
$F_{y}$ & 23 & -3.67 & 0.82 & -0.44 & 1.44 \\
$F_{L}$ & 23 & -0.92 & 1.27 & 0.23 & 0.52 \\
$F_{H \text { GlaS }_{a}}$ & 23 & -0.57 & 1.36 & 0.08 & 0.41 \\
$F_{\text {HGlaSTopo }}$ & 23 & -0.60 & 0.61 & 0.14 & 0.30 \\
\hline
\end{tabular}

LiDAR data. A detailed view of the upper catchment area of Glyssibach is given in Fig. 14. Here the range above erosion and deposition is mapped, starts at $-0.45 \mathrm{~m}$, respectively $0.45 \mathrm{~m}$ of elevation difference. One can clearly identify the landslide of Baalen (1050 $\mathrm{m}$ above sea level). The area with landslide erosion activity at Baalen - was calculated to be $12500 \mathrm{~m}^{2}$, with an average erosion depth of $4.5 \mathrm{~m}$. Since the whole area of the landslide lies in a steep range an elevation error as a function of the slope inclination had to be considered. Due to the quadratic relationship between slope and elevation and the heterogeneity of the Baalen relief, we used the median of the slope distributions as the average value to estimate the elevation error. For the landslide of Baalen the median slope inclination is $30^{\circ}$, so the elevation error here was estimated with $0.40 \mathrm{~m}^{3} / \mathrm{m}^{2}$ for Gly $T_{a}$ respectively $0.51 \mathrm{~m}^{3} / \mathrm{m}^{2}$ for GlyTTopo $a$ (cp. Fig. 12).

Subtracting the terrain models Gly $T_{b}$ and Gly $T_{a}$ for the above described landslide area, a total eroded volume of $52700 \mathrm{~m}^{3}$ was calculated. Considering the estimated elevation error yields to an upper and lower bound of $5000 \mathrm{~m}^{3}$. By subtracting the terrain model Gly $T_{b}$ with the Toposys generated elevation model GlyT Topo $a$ a total eroded volume of $53700 \mathrm{~m}^{3}$ could be obtained. Here the elevation error considering an average slope inclination of $30^{\circ}$ and GlyT Topo ${ }_{a}$ yields to an upper and lower bound of $6400 \mathrm{~m}^{3}$. Table 11 gives an overview of the results from the local event documentation and the LiDAR data. The symbol $\Delta$ describes the relation between field estimate and LiDAR analysis.

Comparing the estimated values of the local event documentation with the calculated results from the LiDAR data, it is evident that the disagreement between the two volume estimates for the landslide at Baalen is quite large.

As described before, strong vertical and lateral erosion processes - except for the upper region of the catchment area - have been observed. Starting from the point where the landslide of Baalen hit the channel down to the beginning of the deposition (Fig. 15), a balance of eroded respectively deposited material has been estimated for the local event documentation (NDR Consulting Zimmermann/Niederer und Pozzi Umwelt AG, 2006). In Fig. 15 the range of erosion and deposition is again mapped at $-0.45 \mathrm{~m}$ respectively $0.45 \mathrm{~m}$ of elevation difference.

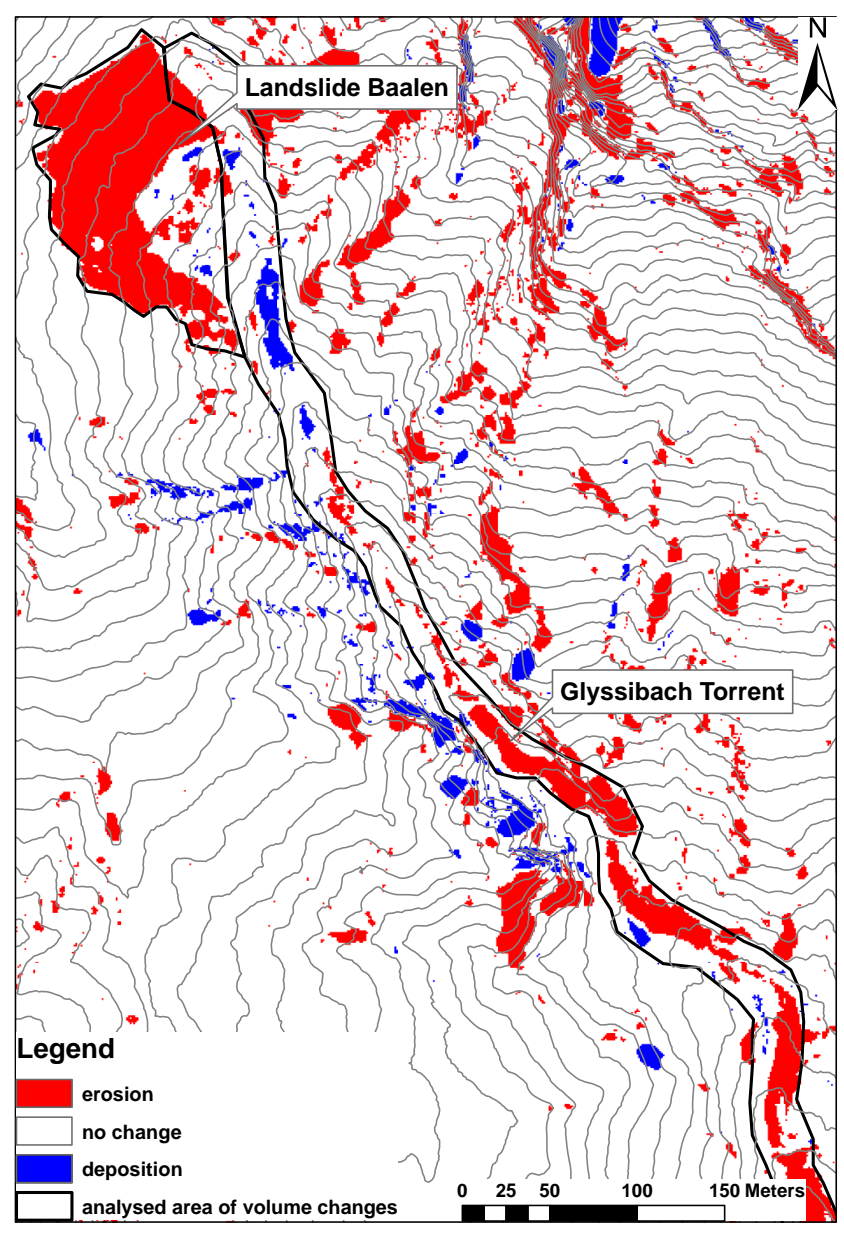

Fig. 14. Subtraction-grid $\left(\mathrm{Gly} T_{a}-\mathrm{Gly} T_{b}\right)$ of the upper catchment area of Glyssibach; red: erosion activity; blue:deposition activity.

The debris material, eroded by the flow event 2005, was estimated between $30000 \mathrm{~m}^{3}$ and $45000 \mathrm{~m}^{3}$. Using the $\mathrm{Li}^{-}$ DAR generated elevation models, Gly $T_{b}$ and Gly $T_{a}$, the amount of eroded material for the considered stream reach was calculated to be $31500 \mathrm{~m}^{3}$. With an average channel slope of $18^{\circ}$, the elevation error was determined with $0.28 \mathrm{~m}^{3} / \mathrm{m}^{2}$, specifying an upper and lower volume errorbound of $\pm 17500 \mathrm{~m}^{3}$ for the surveyed channel reach. 
Table 11. Comparison of estimated results from the local event documentation (NDR Consulting Zimmermann/Niederer und Pozzi Umwelt AG, 2006) and the calculated results from LiDAR data for the landslide Baalen in the Glyssibach catchment. (avg. denotes average).

\begin{tabular}{lccccc}
\hline & $\begin{array}{c}\text { active area } \\
{\left[\mathrm{m}^{2}\right]}\end{array}$ & $\begin{array}{c}\text { avg. erosion } \\
\text { depth }[\mathrm{m}]\end{array}$ & $\begin{array}{c}\text { avg. } \\
\text { slope }\left[{ }^{\circ}\right]\end{array}$ & $\begin{array}{c}\text { avg. eroded } \\
\text { volume }\left[\mathrm{m}^{3}\right]\end{array}$ & $\Delta[-]$ \\
\hline Local event documentation & - & - & - & 30000 & - \\
LiDAR analysis GlyT $_{a}$ & 12500 & 4.5 & 30 & $52700 \pm 5000$ & $1.6-1.9$ \\
LiDAR analysis GlyTTopo $a$ & 12500 & 4.5 & 30 & $53700 \pm 6400$ & $1.6-2.0$ \\
\hline
\end{tabular}

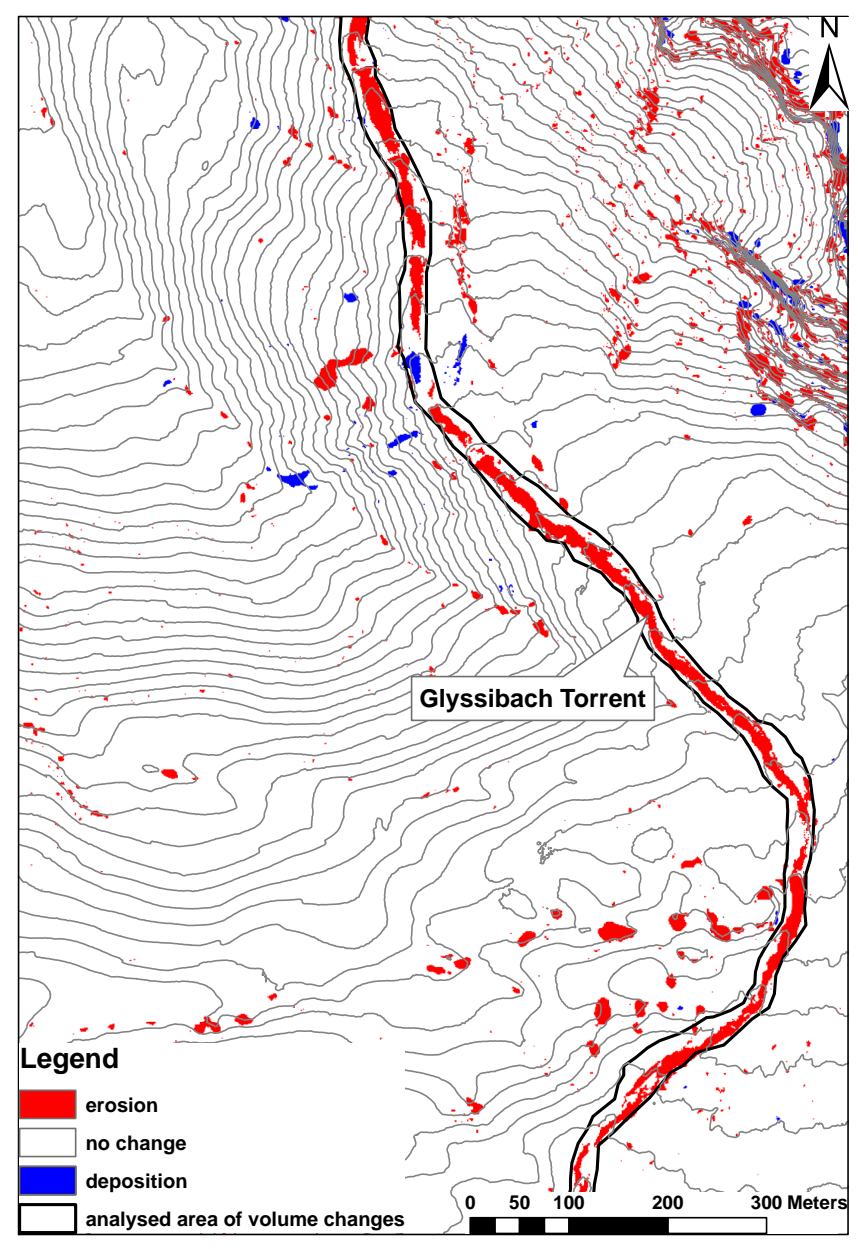

Fig. 15. Subtraction grid $\left(\mathrm{Gly} T_{a}-\mathrm{Gly} T_{b}\right)$ of the active reach of the Glyssibach torrent; red: erosion activity; blue:deposition activity.

The amount of eroded material using the Toposys generated elevation model GlyT Topo $a$ was calculated with $39100 \mathrm{~m}^{3}$. The related elevation error due to the average slope inclination was determined with $0.32 \mathrm{~m}^{3} / \mathrm{m}^{2}$, specifying an upper and lower volume error-bound of $\pm 19800 \mathrm{~m}^{3}$. As shown in Table 12, the estimated volume of the local event documentation is in a good agreement with the calculated volume from the LiDAR generated elevation models.
The debris material triggered by the landslide of Baalen combined with the eroded material over the entire channel, results in a potential value for the deposited volume at Brienz. The comparison in Table 13 shows that the analysed deposition volume using LiDAR data is larger than the estimated volume from the local event documentation.

\subsection{Analysis of the debris flow event Glattbach}

The mobilised material emanated mainly from strong vertical and lateral erosion processes throughout the channel bed. Gertsch and Kienholz (2005) reported a total volume of eroded material along the channel of about $7000 \mathrm{~m}^{3}$. They further estimated the deposition volume to be approximately $4000 \mathrm{~m}^{3}$. The deposition area determined for the local event documentation amounts to $30000 \mathrm{~m}^{2}$. The expected average deposition high is therefore about 0.13 to $0.23 \mathrm{~m}$, possible smaller than the calculated elevation error $F_{H \text { GlaSTopo }_{a}}$ (see Table 10). Due to a correction of the elevation and local error, the elevation models $\left(\mathrm{Gla}_{b}, \mathrm{Gla}_{a}\right.$ and GlaT Topo ${ }_{a}$ ) will be treated equally. Further it is assumed that the standard deviations of both errors are compensated over the entire surface by reason of the high resolution LiDAR models. If we consider the rough estimation of volume and deposition area (almost a factor of 2) from local event documentation, we conclude that a higher average elevation error compared to the average deposition, does not influence the calculation of the volume to a great extent.

Here, the fan region of Glattbach is used to calculate, the deposited volume from the difference of the terrain elevation models after the event and before the event $\left(\mathrm{Gla}_{a}-\right.$ $\mathrm{Gla}_{b}$ and GlaT Topo $\left.a-\mathrm{Gla}_{b}\right)$. A detailed view of the deposition region of the Glattbach debris flow event is given in Fig. 16 again with a lower and upper boundary of $-0.45 \mathrm{~m}$ and $0.45 \mathrm{~m}$ for erosion respectively deposition activity. With an average slope gradient of $8^{\circ}$, the elevation error was calculated to $0.12 \mathrm{~m}^{3} / \mathrm{m}^{2}$ for the LiDAR point model Gla $T_{a}$ and $0.14 \mathrm{~m}^{3} / \mathrm{m}^{2}$ for the Toposys elevation model GlaT Topo $a$. Using LiDAR data, a total deposited volume of $7400 \mathrm{~m}^{3}$ with an upper and lower error-bound of $\pm 3600 \mathrm{~m}^{3}$ was calculated. The analysed deposition volume using the Toposys generated elevation model belongs to $9000 \mathrm{~m}^{3}$ with an upper and lower error-bound of $\pm 4150 \mathrm{~m}^{3}$. Table 14 compares the estimated 
Table 12. Comparison of estimated results from the local event documentation (NDR Consulting Zimmermann/Niederer und Pozzi Umwelt AG, 2006) and the calculated results from LiDAR data for the active reach at Glyssibach (avg. denotes average).

\begin{tabular}{lcccc}
\hline & $\begin{array}{c}\text { active area } \\
{\left[\mathrm{m}^{2}\right]}\end{array}$ & $\begin{array}{c}\text { avg. } \\
\text { slope }\left[{ }^{\circ}\right]\end{array}$ & $\begin{array}{c}\text { avg. eroded } \\
\text { volume }\left[\mathrm{m}^{3}\right]\end{array}$ & $\Delta[-]$ \\
\hline Local event documentation & - & - & 40000 & - \\
${\text { LiDAR analysis Gly } T_{a}}^{\text {LiDAR analysis GlyTTopo }} a$ & 61900 & 18 & $31500 \pm 17500$ & $0.4-1.2$ \\
\hline
\end{tabular}

Table 13. Comparison of estimated results from the local event documentation (NDR Consulting Zimmermann/Niederer und Pozzi Umwelt AG, 2006) and the calculated results from LiDAR data for the total deposited volume at Glyssibach (avg. denotes average).

\begin{tabular}{lccc}
\hline & $\begin{array}{c}\text { avg. deposited } \\
\text { area }\left[\mathrm{m}^{2}\right]\end{array}$ & $\begin{array}{c}\text { avg. deposited } \\
\text { volume }\left[\mathrm{m}^{3}\right]\end{array}$ & $\Delta[-]$ \\
\hline Local event documentation & - & $(50000-80000) 65000$ & - \\
${\text { LiDAR analysis Gly } T_{a}}_{\text {LiDAR analysis GlyTTopo }}$ & 45000 & $84200 \pm 22500$ & $1.0-1.6$ \\
\hline
\end{tabular}

deposit volume of the local event documentation (Gertsch and Kienholz, 2005) with values calculated in this study.

\subsection{Comparison}

The volume estimates based on LiDAR data are in reasonable agreement with the estimated values of the event documentations. For this study, the LiDAR based volume estimates tended to be higher than the field based estimates. Further, higher deviations in contrast to the event documentations are noticed in steeper regions (cp. landslide Baalen; Table 11). Compared to the event documentations, the LiDAR estimates range between 1.0 to 1.8 for the Glyssibach debris flow event and 0.7 to 2.4 for the Glattbach debris flow event.

Comparing the terrain models generated from LIDAR data with the terrain models generated from Toposys (Gly $T_{a}$, $\mathrm{Gla}_{a}$ and GlyTTopo $a$, GlaTTopo ${ }_{a}$ ), a tendency of higher volumes estimates for the elevation models from Toposys, can generally be noticed (cp. Tables 11, 12 and 14). Using LiDAR methods, this certainty has to be considered when analysing sediment transport in mountain torrents with debris flow potential tributaries.

\section{Discussion}

The use of LiDAR data opens new prospects for the volume assessment of debris flow events. Based on this study the following most important advantages and disadvantages of using LiDAR data are summarised.

In order to generate digital elevation models from commercial LiDAR point-data, the method of natural neighbour (NN) has been found to be an adequate interpolation technique. Due to its high point density, an actual resolution of

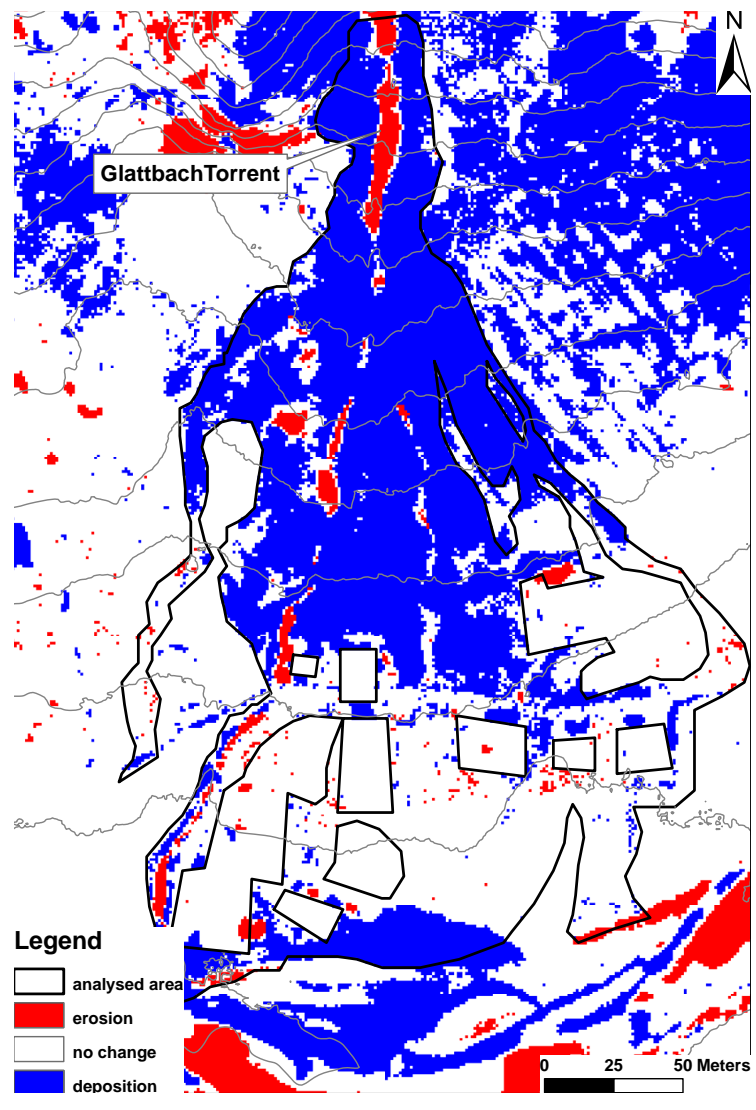

Fig. 16. Subtraction-grid $\left(\mathrm{Gla} T_{a}-\mathrm{Gla} T_{b}\right)$ of the deposition area of Glattbach. Some areas with buildings were excluded from the analysis of volume changes; red: erosion activity; blue:deposition activity. 
Table 14. Comparison of estimated results from the local event documentation (Gertsch and Kienholz, 2005) and the calculated results from LiDAR data for the total deposited volume at Glattbach (avg. denotes average).

\begin{tabular}{lllll}
\hline & $\begin{array}{l}\text { avg. deposited } \\
\text { area }\left[\mathrm{m}^{2}\right]\end{array}$ & $\begin{array}{l}\text { avg. } \\
\text { slope }\left[{ }^{\circ}\right]\end{array}$ & $\begin{array}{l}\text { avg. deposited } \\
\text { volume }\left[\mathrm{m}^{3}\right]\end{array}$ & $\begin{array}{l}\text { relation factor } \\
{[]}\end{array}$ \\
\hline Local event documentation & 30000 & 8 & $(4000-7000) 5500$ & 1.0 \\
${\text { LiDAR analysis Gla } T_{a}}^{\text {LiDAR analysis GlaTTopo }} a$ & 30000 & 8 & $9000 \pm 3600$ & $0.7-2.0$ \\
\hline
\end{tabular}

digital elevation models with a grid size of $1 \mathrm{~m} \times 1 \mathrm{~m}-$ or even finer - can be realised.

LiDAR generated terrain models are a suitable tool for the determination of geomorphologic changes. Erosion and deposition zones can easily be identified, presenting an overview of the geomorphological situation of the surveyed region. This applies particularly for a balance of eroded or deposited material - independently of the analysed process. Inaccuracies have been found in identifying pseudocontrol points and ranges of steep slope situations. Here larger uncertainties may be expected. Pseudocontrol points surrogate the lack of ground control points, making a correction of digital elevation models possible. Their identification can be difficult whereas the filtering of LiDAR data can have a distinct impact on various morphologic features (houses, roads, bridges, etc.). For the analysis of landslides as well as for debris flows a potential elevation-error as a function of the slope inclination has to be considered. For analysing channel based processes with changing erosion- and deposition behaviour (as for fluvial sediment transport) it is therefore recommended to discretise the active stream into homogeneous slope zones. LiDAR generated surface models could also be used to investigate erosion processes of streamside trees linked to an estimation of the magnitude of potential woody debris.

Within a classic event documentation often an exact knowledge of the local environment is presupposed. Due to an easy integration of LiDAR generated models into a geographical information system (GIS), the spatial interpretation of LiDAR data is simple.

Water levels cannot be measured by using LiDAR techniques, based on the physical fact that measuring points on water surfaces are not possible. For medium to high discharges the detection of the channel bed is therefore not possible. Here LiDAR bathymetry could be adequate. Bathymetric systems transmit two light waves, one in the infrared and one in the green spectrum, detecting two returns that delineate the water surface and the water ground. However,only for torrents and mountain streams characterised by low submergence and protruding boulders, the channels bed elevation can be estimated.

The aquisition of airborne LiDAR data is still relatively expensive, and therefore measuring campaigns may be feasible only after events with larger sediment deposits.

\section{Conclusions}

For event documentations it is common to estimate the volumes of transported sediment after debris flow events based on an expert assessment in the field. However these estimates are often associated with wide ranges between minimum and maximum estimates of sediment volumes (sometimes up to a factor of 2). Post-event surveys of hazardous alpine events greatly benefit from the use of up-to-date technologies. This study examined a LiDAR based method to calculate deposited and eroded volumes due to geomorphologic changes caused by debris flow events. It is shown that the calculated volumes correspond reasonably well to approximate field estimates of the event documentations. Pastevent terrain analysis combined with LiDAR data can therefore be useful for a fast and comprehensive assessment of the deposited and eroded sediments.

Acknowledgements. We thank the Swiss Ministry for Environment (BAFU) for the support of this study and for providing the LiDAR DTM for the situation after the event 2005. The used LiDAR DTM and DOM before the event 2005 were provided by the Swiss Federal Office of Topography (swisstopo). Unless otherwise noted all figures showing LiDAR analysed results are based on "DTMAV DOM-AV (C2008 BAFU" and "DTM-AV DOM-AV (C2008 swisstopo" (DV033492.2). We also thank Jörg Häberle and the Forest Department of the Canton of Berne for organising the past event LiDAR measurements. Thanks are also due to Martin Hägeli and Christian Ginzler from the Swiss Federal Research Institute WSL for their support.

Edited by: T. Glade

Reviewed by: L. Marchi and another anonymous referee

\section{References}

Axelsson, P.: DEM generation from laser scanner data using adaptive TIN models, International Archives of Photogrammetry and Remote Sensing, 23, 111-118, 2000.

Bezzola, G. R. and Hegg, C. (Eds.): Ereignisanalyse Hochwasser 2005, Teil 1 - Prozesse, Schäden und eine erste Einordnung, 0707, Bundesamt für Umwelt BAFU, Eidgenssische Forschungsanstalt WSL. Umwelt-Wissen, 2007.

Cavalli, M. and Marchi, L.: Characterisation of the surface morphology of an alpine alluvial fan using airborne LiDAR, Nat. 
Hazards Earth Syst. Sci., 8, 323-333, 2008,

http://www.nat-hazards-earth-syst-sci.net/8/323/2008/.

Cavalli, M., Tarolli, P., Marchi, L., and Dalla Fontana, G.: The effectiveness of airborne LiDAR data in the recognition of channelbed morphology, Catena, 73, 249-260, 2008.

Costa, J. E.: Physical Geomorphology of Debris Flows, in: Developments and Applications of Geomorphology, edited by: Costa, J. E. and Fleisher, P., pp. 268-317, Springer-Verlag Berlin Heidelberg, 1984.

Gertsch, E. and Kienholz, H.: Ereignisdokumentation StorMe, Unwetter 22./23. August 2005, Gemeinde Lütschental, Tech. rep., Angewandte Geomorphologie und Naturrisiken AGNAT; Geographisches Institut Universität Bern, 2005.

Häberli, J.: Unwetter 2005: Organisation und Anwendung verschiedener Bilddaten im Kanton Bern, Geomatik, 9, 498-501, 2006.

Hodgson, M. E., Jensen, J. R., Smidt, L., Schill, S., and Davis, B.: An evaluation of LIDAR- and IFSAR-derived digital elevation models in leaf-on conditions with USGS Level 1 and Level 2 DEMs, Rem. Sens. Environ., 84, 295-308, 2003.

Hooke, R. L. B. and Rohrer, W. R.: Processes on arid-region alluvial fans, J. Geol., 75, 438-460, 1967.

Ikeya, H.: Debris flow and its countermeasures in Japan, Bulletin International Ass. Engineering Geol., 40, 15-33, 1989.

Iverson, R. M., Schilling, S. P., and Vallance, J. W.: Objective delineation of lahar-inundation hazard zones, GSA Bull., 110, 972984, 1998

James, L. A., Watson, D. G., and Hansen, W. F.: Using LiDAR data to map gullies and headwater streams under forest canopy: South Carolina, USA, Catena, 71, 132-144, doi:10.1016/j.catena.2006. 10.010, 2007.

Kraus, K.: Eine neue Methode zur Interpolation und Filterung von Daten mit schiefer Fehlerverteilung., Österreichische Zeitschrift für Vermessung und Geoinformation (VGI), 1, 25-30, 1997.

Kraus, K. and Pfeifer, N.: Advanced DTM generation from LiDAR data, International Archives of Photogrammetry and Remote Sensing, 24, 23-30, 2001.

Landtwing, S.: Airborne Laser Scanning - Genauigkeitsinformationen für den Auswertungsprozess, Master's thesis, ETH - Eidgenössische Technische Hochschule Zürich, 2005.

Legros, F.: The mobility of long-runout landslides, Eng. Geol., 63, 301-331, 2002.

Lillesand, T. M., Kiefer, R. W., and Chipman, J. W.: Remote Sensing and Image Interpretation, Wiley, fifth edn., 2004.
Lloyd, C. and Atkinson, P.: Deriving DSMs from LiDAR data with kriging, Int. J. Rem. Sens., 23, 2519-2524, 2002.

Marchi, L., Cavalli, M., Grisotto, S., Mazzorana, B., Trevisani, S., and Zannoni, A.: Interreg III Project Alpine Space Disaster Information System of Alpine Regions (DIS-ALP) Work Package 7 - Innovative Tools for Information Collection, unpublished, 2006.

Mizuyama, T., Kobashi, S., and Ou, G.: Prediction of debris flow peak discharge, in: International Congress Interpraevent, vol. 4, pp. 99-108, 1992.

NDR Consulting Zimmermann/Niederer und Pozzi Umwelt AG: Lokale lösungsorientierte Ereignisanalyse, Glyssibach, Bericht zum Vorprojekt, Tech. rep., Tiefbauamt des Kantons Bern, 2006.

Optech: Manufacturer of world class LiDAR solutions, http://www. optech.ca, 26 February 2008.

Rickenmann, D.: Empirical Relationships for Debris Flows, Nat. Hazards, 19, 47-77, 1999.

Rickenmann, D., Hunzinger, L., and Cosandey, A.-C.: Gerinneprozesse, in: Ereignisanalyse Hochwasser 2005. Teil 1 Prozesse, Schäden und erste Einordnung., edited by: Bezzola, G. R. and Hegg, C., 0707, pp. 163-180, Bundesamt für Umwelt - BAFU, Eidgenössische Forschungsanstalt WSL, Umwelt-Wissen, 2007.

Scheidegger, A. E.: On the prediction of the reach and velocity of catastrophic landslides, Rock Mech., 5, 231-236, 1973.

Takahashi, T., Sawada, H., Suwa, T., Mizuyama, T., Mizuhara, K., Wu, J., Tang, B., Kang, Z., and Zhou, B.: Japan-China joint research on the prevention from debris flow hazards, in: Research Report,Japanese Ministry of Eductaion, Science and Culture, Int. Scientific Research Program, edited by: Japanese Ministry of Eductaion, S. and Culture, 03044085, 1994.

TopoSys: Topographische Systemdaten GmbH., http://www. toposys.de/, 29 December 2007.

Vosselman, G.: Slope based filtering of laser altimetry data, International Archives of Photogrammetry and Remote Sensing, 23, 935-942, 2000.

White, S. A. and Wang, Y.: Utilizing DEMs derived from LiDAR data to analyze morphologic change in the North Carolina coastline, Remote Sens. Environ., 85, 39-47, 2003.

Woolard, J. W. and Colby, J. D.: Spatial characterization, resolution, and volumetric change of coastal dunes using airborne LIDAR: Cape Hatteras, North Carolina, Geomorphology, 48, 269287, 2002. 